




\section{GROWING PLANTS WITHOUT SOIL}

\section{Wade W. McCall and Yukio Nakagawa}

Growing plants without soil is not new. Man started agricultural pursuits by growing plants in soil but as the knowledge of plant nutrition increased, he learned to grow plants in artificial media, such as quartz, sand, gravel, etc. The next step was to eliminate solid media and to grow plants directly in solutions. By 1860 the principles of growing plants in solution were well understood, and satisfactory solutions for supplying nutrients to plants were developed. It was not until 1929, however, that the commercial possibilities of this method were realized. The idea of growing plants in solution instantly became popular, and many articles about it appeared in popular media. Many exaggerated and wholly unfound claims were made for this method of growing plants. This interest has been maintained until this day. This circular is intended to supply information on growing plants without soil.

\section{Principles of Growing Plants Without Soil}

A knowledge of the principles of plant physiology and horticulture or agronomy involved in crop production is necessary for growing plants in the soil or without soil. By supplying nutrients and water to plants, only two of the physiological process of the plant are satisfied. The significance of other interrelated processes must be understood, especially photosynthesis, respiration, transpiration, and reproduction. In addition, when establishing an installation for growing without soils, many problems of engineering and economics must be considered as well. 


\section{Justification for Crop Production Without Soil}

Soil is the natural habitat for plants. It supplies support, nutrients, and water. Where an adequate supply of productive soil is available, growing plants without soil is not practical. However, where good soil is not available, where maintenance of favorable soil conditions is too expensive, or where growth of high-value out-of-season crops is contemplated, growing plants without soil may be desirable.

With adequate water supply but where soil is not available, very favorable climates are needed to favor growing plants without soil. The U.S. Army during World War II used this method of producing fresh vegetables for troops stationed on Ascension Island. Many oil companies also use this method of producing fresh vegetables for personnel stationed on barren and/or inaccessible islands, such as Aruba and Curacao.

Growing plants without soil may be desirable for health reasons. After World War II, large installations were built in Japan to reduce the incidence of disease caused by the use of night soil as fertilizer for crops. However, rigid sanitation methods are required for full protection. In addition, growing plants without soil may provide an excellent means of physical or occupational therapy for people who cannot lead a full, normal life.

Many areas, such as Hawaii, have a limited amount of available land suitable for agriculture. This land is of high value so that a system of crop production suitable for forcing high-value crops is necessary. Growing plants without soil provides a means of forcing crops for greater production. Such installations may be built near markets where the produce may be marketed soon after harvesting. This allows the product to ripen on the plant. Such products are of higher quality and have better taste than those harvested before maturity and held for long periods in distribution channels before they reach the consumer.

Growing plants without soil is suitable for use by homeowners and other amateur gardeners. The instructions contained in this circular are suitable for use by the amateur or the commercial grower.

\section{Limitations of Commercially Growing Plants Without Soil}

The commercial application of the system of growing plants without soil has not been as widespread as expected. Two factors have limited soilless methods of production: First, economic considerations and second, commercial growers' unfamiliarity with the management of growing without soil.

Growing plants without soil is costly and needs expert supervision. The initial cost is very high. This is especially true here in Hawaii, where material and labor costs are very high.

Expert supervision is necessary to cope with the technical difficulties often met with in this method of production. Some of these problems are: proper preparation of tanks or beds used to grow crops; character 
of the water used; adjustment of acidity of the solution; frequency of applying the nutrient solution; frequency of renewing, adjusting, or discarding the nutrient solution; toxic substances from the tanks or beds; disease and insect control; and many engineering problems associated with this method of growing plants.

Growing plants without soil demands a knowledge of all factors of plant growth-selection of proper varieties, habits of plant growth of the crop selected, climatic needs or adaptations of the crop, and pollination requirements. Sanitation measures to prevent disease and insect infestation are essential. In Hawaii, wind protection is a major consideration. In other words, to establish an installation for growing plants without soil, the same knowledge is required as is needed for successful crop production in soils.

Any plant can be grown without soil. Tomatoes, cucumbers, lettuce, beans, potatoes, corn, oats, fruits, flowers, and many others have all been grown without soil. However, the choice of the plant to be grown depends upon very careful analysis of market demands in relation to the cost of production and to the availability of labor and supervision needed. Tomatoes are the only crop produced commercially, without soil, in Hawaii. At present, there are in Hawaii four commercial installations growing tomatoes. These have varying degrees of success depending upon how well the producer recognizes and solves the essential considerations in growing plants by this method.

\section{Methods of Growing Plants Without Soil}

There are four methods of growing plants without soil-water culture, sand culture, gravel culture, and adsorbed-nutrient technique. The first three depend upon the use of a solution containing plant nutrients, and the last has the plant nutrients adsorbed on the surface of synthetic resins similar to soil-clay particles. Materials such as cinders, vermiculite, clinkers, etc., may be used but these are essentially the same as sand or gravel.

\section{Water Culture}

The water culture method is known as hydroponics or solution culture. Today, all methods of growing plants with nutrient solutions are known as "hydroponics" although technically the term refers to water culture only.

In hydroponics, plants are grown with their roots partially submerged in a solution containing nutrients for plant growth. The plants are held upright on wire or on wooden or metal supports. The solution is contained in tanks which vary in size. The most suitable tanks are 6 to 8 inches deep. The width and length of the tank depend upon the location of its use. Three feet is a convenient width for easy access for working. Some installations use a "standard" tank 8 inches deep, 4 feet wide, and 50 feet long. Actual dimensions should be those most convenient for 
the operation and the location. Tanks may be made of metal, glass, wood, plastic, concrete, or other suitable materials. Metal and concrete tanks should be coated with an inert material such as asphalt emulsion paint to prevent damage to plants from toxic substances contained in metal and concrete. Wooden and concrete tanks should be waterproofed to prevent the loss of solution. Glass and translucent plastic containers should be painted to eliminate light to prevent the growth of algae in the solution. Tar and most common paints contain substances toxic to plants and should not be used. Concrete and wooden tanks should be thoroughly leached before use.

A liquid solution does not provide support to the roots of plants, so a means must be provided to uphold the plant but allow the roots to extend down into the solution. Wire mesh, hardware cloth, wooden strips, or other support materials may be used. Wire or metal supports should be coated with asphalt emulsion paint to prevent corrosion and/or toxicity to the plants. These supports must be mounted on a frame built to fit the tank and designed to prevent sagging of the support material. Cork, glass wool, cotton, etc., may be used as supports for small containers. A layer of porous bedding material should be placed over the support on the frame to provide a place for tubers, bulbs or other plant parts to develop. This layer should be 3 to 4 inches thick-thicker for plants that develop tubers or fleshy roots. Excelsior, peat moss, sawdust, shavings, or similar materials may be used. Materials that may be toxic to plants should be avoided. For plants that develop tubers and fleshy roots, finer materials are needed. Fine materials also should be used when seeds are to be planted in the material and allowed to develop. The bed should give close contact of moist material and the seed. In all cases, the beds should be porous and should have free access of air. Great care should be exercised to prevent the bed from becoming waterlogged.

When the plants are young, the solution level should be approximately 1 inch below the bedding material. As the plants mature, additional air space is required, and the solution level should be dropped to 2 or 3 inches below the bedding material. The bottom of the bed should not be immersed in the solution because this causes waterlogging, poor aeration, and undesirable bacterial decomposition. Plants should have two-thirds of their root system immersed in the solution. As the plants grow, they will absorb water and plant nutrients; some water will evaporate so that regular additions of the solution is required to maintain solution level and nutrient content in the tanks.

Solution in the tank should supply the nutrients necessary for plant growth. ${ }^{1}$ The solutions may be made from commercially available fertilizer salts, chemically pure salts, or ready-made mixtures. Many formulae have

${ }^{1}$ For discussion of nutrients essential to plant growth, see McCall, Wade W. 1970. What's in That Fertilizer Bag? University of Hawaii Coop. Ext. Ser. Circular 441. 




Figure 1. Growing plants without soil is often used in experimental work to determine plant needs. This is water culture to determine nutrient requirements of the tomato plant. The plants are supported by cotton inserted around the support over the containers. The air supply is furnished from a compressed air source. Each container has been painted to protect the solution from light.

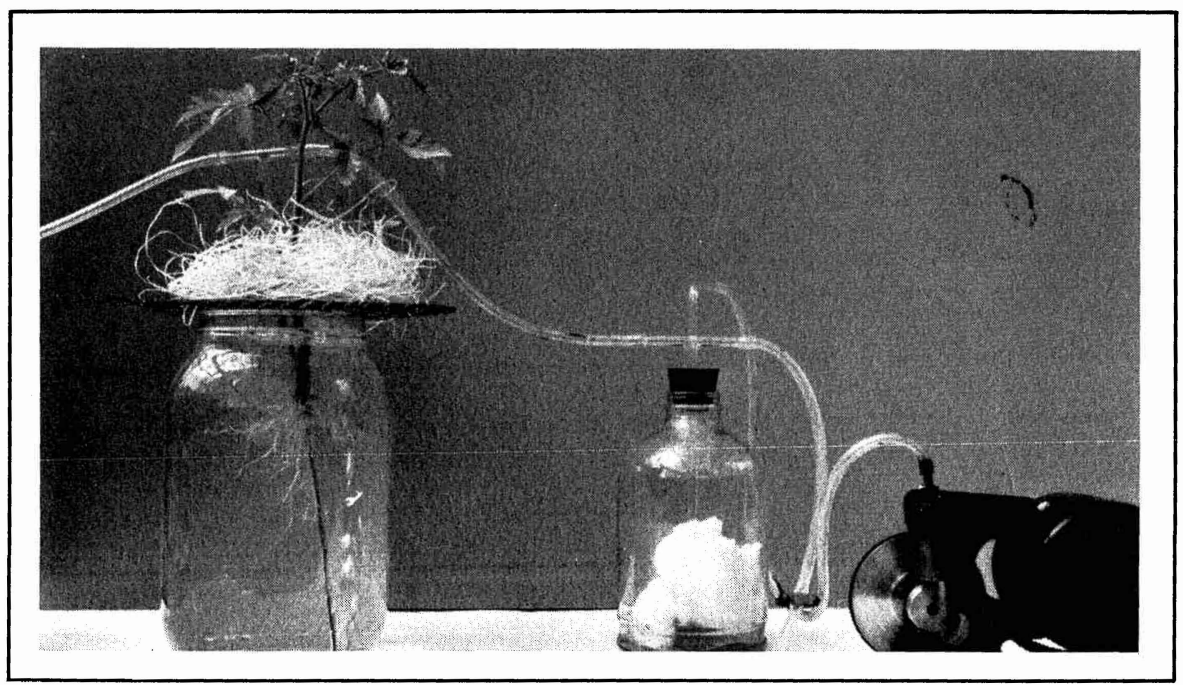

Figure 2. Growing plants in the water-culture method. A support is needed for the bedding material used to hold plants in upright position. Woven wire painted with asphalt emulsion paint was used to support excelsior bedding material. Air is bubbled through the solution with bubbles $1 / 2$ inch apart to supply needed oxygen. Note the root growth of the plant. The clear container was used to show relationship of roots and air supply in the container. 
been developed for nutrient solutions. No one nutrient solution is superior to any other solution. Solutions developed for various crops are given in Tables 1,2,3, and 4. Many other formulae may be found in the references given at the end of this circular.

Table 1. A nutrient solution used by some commercial growers

\begin{tabular}{lccc}
\hline & Grams/liter & Milligrams/liter & Ounces/100 gals \\
\hline Sodium nitrate & 0.76 & 760 & 10.5 \\
Potassium sulfate & 0.24 & 240 & 3.3 \\
Monocalcium phosphate & 0.25 & 250 & 3.5 \\
$\quad$ (Triple superphosphate) & & & \\
Magnesium sulfate & 0.71 & 710 & 10.0 \\
Potassium nitrate & 0.27 & 270 & 3.8 \\
Calcium nitrate & 0.76 & 760 & 10.5 \\
Iron sulfate* & 0.03 & 30 & 0.5 \\
\hline
\end{tabular}

*Iron chelate, iron citrate, or iron tartrate may be used instead of the iron sulfate. Iron may be needed once or twice a week. Add when appearance of plant indicates need.

Table 2. A nutrient solution suggested for general use*

\begin{tabular}{lccc}
\hline & Grams/liter & Milligrams/liter & Ounces/100 gals \\
\hline Monopotassium phosphate & 0.14 & 140 & 2.0 \\
Potassium nitrate & 0.55 & 550 & 8.0 \\
Calcium nitrate & 0.88 & 880 & 12.0 \\
Magnesium sulfate & 0.71 & 710 & 10.0 \\
\hline
\end{tabular}

*Add iron once or twice a week in form of 0.5 percent solution of any of the iron materials from Table 1 at 14.3 ounces per 100 gallons.

Table 3. A nutrient solution suggested for specific crops*

\begin{tabular}{lccccc}
\hline & $\begin{array}{c}\text { For growing flowers and } \\
\text { tomatoes }\end{array}$ & & \multicolumn{2}{c}{$\begin{array}{c}\text { For growing } \\
\text { cucumbers }\end{array}$} \\
\cline { 2 - 3 } \cline { 5 - 6 } & Grams/liter Ounces/100 gals & & Grams/liter Ounces/100 gals \\
\hline Sodium nitrate & 0.49 & 6.2 & & 0.98 & 12.4 \\
Potassium sulfate & 1.58 & 20.1 & & 2.10 & 26.8 \\
Calcium sulfate & 0.40 & 5.1 & & 0.40 & 5.1 \\
Magnesium sulfate & 0.56 & 7.2 & & 0.56 & 7.2 \\
Monocalcium phosphate & 0.27 & 7.2 & & 0.27 & 4.2 \\
Ammonium sulfate & 0.15 & 1.9 & & 0.30 & 3.8 \\
& $*$ Use iron as suggested in Tables 1 and 2. \\
\hline
\end{tabular}


Table 4. Concentrated stock solution of minor elements to be supplied, when needed, to other nutrient solutions*

\begin{tabular}{lccc}
\hline & Grams/liter & Milligrams/liter & Ounces/100 gals \\
\hline Boric acid $\left(\mathrm{H}_{3} \mathrm{BO}_{3}\right)$ & 2.86 & 2860 & 38.00 \\
Manganese chloride $\left(\mathrm{MnCl}_{2} 14 \mathrm{H}_{2} \mathrm{O}\right){ }^{* *}$ & 1.81 & 1810 & 24.00 \\
Zinc sulfate $\left(\mathrm{ZnSO} 4-7 \mathrm{H}_{2} \mathrm{O}\right)$ & 0.22 & 220 & 3.00 \\
Copper sulfate $\left(\mathrm{CuSO}_{4}-5 \mathrm{H}_{2} \mathrm{O}\right)$ & .08 & 80 & 1.00 \\
Molybdic acid $\left(\mathrm{H}_{2} \mathrm{MO}_{\left.4-\mathrm{H}_{2} \mathrm{O}\right)}\right.$ & .02 & 20 & 0.32 \\
\hline
\end{tabular}

*One part of the stock solution is added to 1000 parts of the nutrient solution. This is equivalent to a rate of .8 pint or 12.8 ounces per 100 gallons. Add when nutrient solution is made up or changed.

** Manganese chelate or manganese sulfate may be substituted for maganese chloride.

One liter is 1.056 quarts.

One ounce is 28.35 grams.

One cubic foot contains 7.5 gallons water.

When mixing the solutions, it is generally best to mix the salts in the order given. The salts should be used in the amounts shown to prevent damage to the plants from an oversupply of salts in solution. The amateur may use the figures for ounces in 100 gallons; however, if smaller amounts are to be used, the amounts should be reduced proportionately to maintain the relative strength of the solution. The other figures given are for those who have the proper facilities for more accurate measurements. The solution in Table 4 should be made as a stock solution and one part added to 1,000 parts of either of the solutions in Tables 1, 2, and 3 . This is equivalent to $11 / 2$ cups of the stock solution in 100 gallons of the growing solution. Greater amounts may cause toxicity of one or more of these nutrients to the plant.

Iron may be eliminated from the growing solutions and added as a separate solution or salt. In any case, iron must be added frequently to maintain normal plant growth. If the iron is added separately, dissolve 1 level teaspoonful of iron tartrate, citrate, sulfate, or chelate to 1 quart of water. Add 2 cups of this solution for each 100 gallons of nutrient solution each time iron is needed. Iron sulfate is the least expensive but also the least effective of all these materials.

Control of the acidity $(\mathrm{pH})$ of the solution is necessary. Generally, considerable latitude is permissible, but for best results $\mathrm{pH}$ should be maintained between 5.0 and 6.5. This reaction permits the maximum availability of the nutrients in the solution without the danger of toxicity or fixation due to the effect of $\mathrm{pH}$ upon the nutrients. If the reaction is alkaline, add 0.1 sulfuric $\left(\mathrm{H}_{2} \mathrm{SO}_{4}\right)$, phosphoric $\left(\mathrm{H}_{3} \mathrm{PO} 4\right)$, or nitric $\left(\mathrm{HNO}_{3}\right)$ 
acid a drop at a time until the proper range of acidity is reached. If too acid, add $0.1 \mathrm{~N}$ potassium hydroxide a drop at a time until the proper $\mathrm{pH}$ is obtained. A suitable test kit or $\mathrm{pH}$ meter $^{2}$ is needed to test the $\mathrm{pH}$ after each addition to the solution. The acidity of the water should be adjusted before the salts are added to make the solution. If the solution is to be retained for more than one week, add $1 / 2$ ounce of monopotassium phosphate and 2 cups of the iron solution to each 100 gallons of the growing solution as needed, but at least once a week. The reaction of the solution should be adjusted each time before adding these materials.

Best results are obtained if the solution is tested for available nutrients and the necessary nutrients added as needed. If this is not practical, an arbitrary procedure should be adopted for draining out the solution every week or two and replacing with new solution. The actual time depends upon experience and appearance of the plants.

Lack of oxygen is the most frequent cause of failure in water culture. The lack of oxygen affects availability and uptake of nutrients by the plant. Four to 8 parts per million of oxygen in the solution is required to produce a vigorous, healthy root system. Generally, shallow-open tanks with porous beds facilitate aeration of the roots. However, some plants require air bubbling gently through the solution or circulation of the solution to increase effective aeration of the roots. To supply the oxygen necessary for the plants, air may be pumped through the solution with a pump, by use of compressed air, or with other equipment. Air should be bubbled gently so as not to injure the roots. Bubbles $1 / 2$ to 1 inch apart as they rise through the solution are satisfactory for this purpose.

Because in water culture proper oxygen supply is difficult to maintain and special provisions for plant support are necessary, other methods of growing plants without soil have been developed.

\section{Sand Culture}

Sand culture is sometimes referred to as slop culture, drip culture, or intermittant renewal. Plant nutrients are supplied with solutions, as in water culture. The major difference is that the plants are grown in silica sand or other inert material. The solution is applied to the sand and then allowed to drain off. In this way plant nutrients are supplied, aeration is provided, and the roots of the plant are supported. Additional support may be required for the aerial portions of the plant, especially tomatoes and cucumbers.

Sand $^{3}$ should be medium to coarse in size $(.25 \mathrm{~mm}-2 \mathrm{~mm})$. Finer material drains too slowly and proper aeration is difficult to obtain. The

\footnotetext{
${ }^{2}$ These $\mathrm{pH}$ kits or $\mathrm{pH}$ meters may be obtained from Hawaii Chemical Supply, B.K.H. Division of Van Waters and Rogers, or any other chemical supply company.

${ }^{3}$ Sand is considered a component of soils and identified by size $(.05 \mathrm{~mm}-2 \mathrm{~mm})$. However, when sand is separated from the other soil components (silt and clay) by screening and/or washing, it is no longer considered soil.
} 
sand should be free of lime (non-calcareous), free of other harmful materials, and chemically inert. The coral sands found in Hawaii are primarily calcium carbonate $\left(\mathrm{CaCO}_{3}\right)$ and are not suitable for use in growing plants without soil. Volcanic cinders ${ }^{4}$ found in Hawaii may be satisfactory material but should meet all of the above requirements for sand in order to be safe for use.

The nutrient solution should be added to the sand as needed for the plant's growth. This may be done by allowing the solution to drip on the sand surface at a prescribed rate although this method often results in poor aeration with its attendant problems. The solution may be added once a week and the sand kept moist by adding water. This prevents the danger of nutrient salts accumulating in the sand and consequently injuring the plant. The solution may be added by subirrigating whereby the sand is flooded from beneath and then allowed to drain out or by using a wick to allow the solution to move into the sand by capillary action from a supply below.

To overcome the problem of aeration entailed in using sand, the gravel culture method has been developed.

${ }^{4}$ Some cinders are too alkaline and others are chemically active fixing large amounts of phosphorus and/or releasing toxic substances into solution. However, one commercial installation in Hawaii successfully uses cinder in its installation.
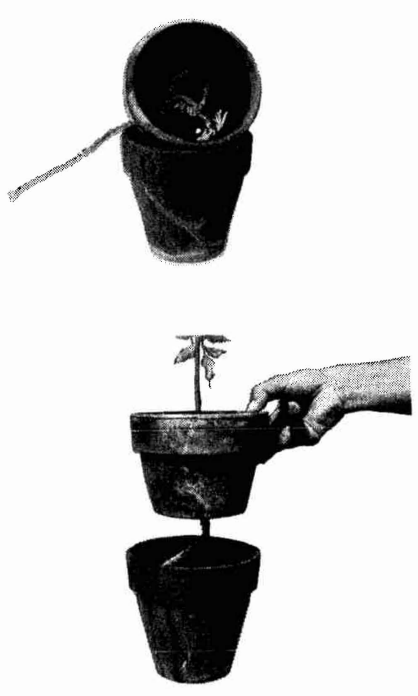

A. A wick extends through bottom of top container and into the solution below.

$B$. The wick is placed into the nutrient solution and draws the solution up by capillarity.

C. The top container sets in the bottom container. Solutions are renewed as necessary.

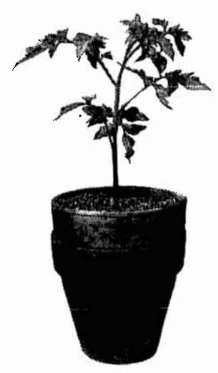

Figure 3. Use of wicks to supply nutrients in sand culture. This is a "self-feeding" type of container. 


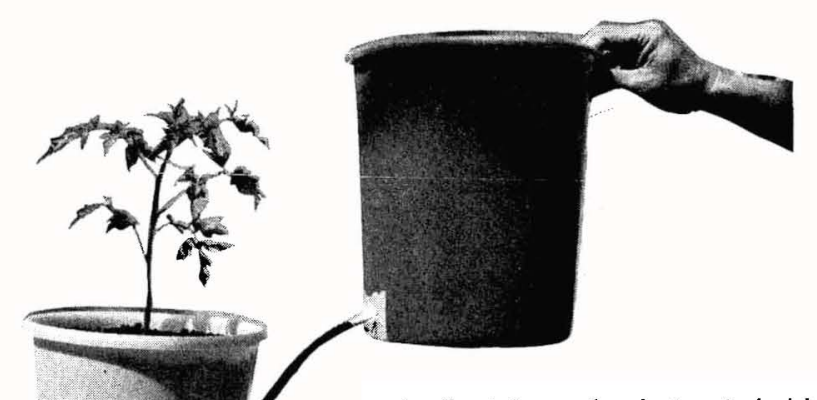

A. Container of solution is held above the level of gravel to fill container to at least one inch from the top of gravel.

Figure 4. Supplying nutrient solutior

\section{Gravel Culture}

In Hawaii, gravel culture is the most widely used method of growing plants without soil. It is similar to the sand-culture method except that the medium is coarser and the method of adding the nutrient solution is more critical. As with sand, the gravel used should be non-calcareous, free of harmful substances, and chemically inert. The nutrient solution used is the same as for sand and water culture. Containers used may be the same as for water culture; however, the solution must drain off so that none remains in the container. The nutrient solution may be added by the gravity method or the drip method. The former is quite convenient and consists of a container of solution raised above the gravel level to fill the container of gravel and lowered below the gravel level to drain the container. If the installation is a large one, the same results may be obtained by using pumps to bring the solution from a storage tank into the containers of gravel and then allowing the solution to drain off by gravity. The nutrient solution may also be added by using sprinklers or other means of flooding from the surface, then allowing the solution to drain away.

Some operators prefer to add dry fertilizer salts to the surface of the sand or gravel and then water them into the growing media. This method 


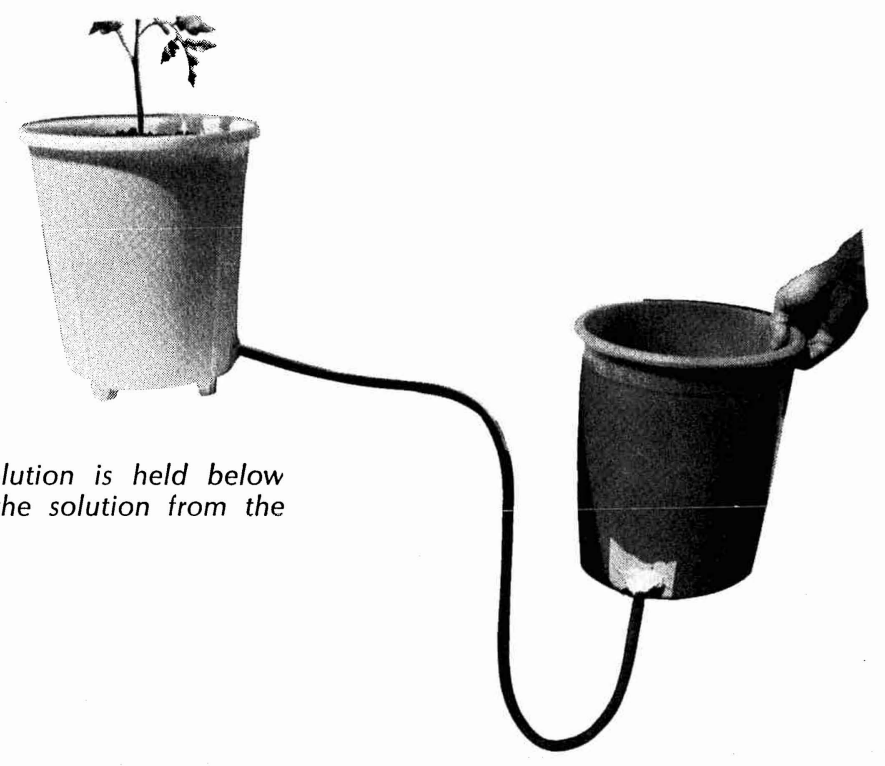

Container for solution is held below gravel to drain the solution from the gravel.

vity-feed method in sand or gravel culture.

of dry feeding may cause several problems. (1) It may cause uneven distribution of the nutrients over the media and uneven watering of the material throughout the media. (2) It is a more difficult method for control of the supply of plant nutrients. (3) It increases the danger of damage to plants due to excess salts. If dry feeding is to be used, apply the salts every 10 days to 2 weeks and maintain moisture in the media by adding water as needed.

\section{Adsorbed-Nutrient Culture}

This method differs from the others in that the plant nutrients are adsorbed on synthetic ion-exchange resins similar to soil-clay particles. These exchange materials are then mixed with sand or gravel to supply the plant's needs much the same way as colloids in natural soil supply nutrients for plant use. This method has produced some excellent results in experimental work done by the senior author. The ion-exchange materials used are so expensive at the present time that this method is not suitable for commercial exploitation. 


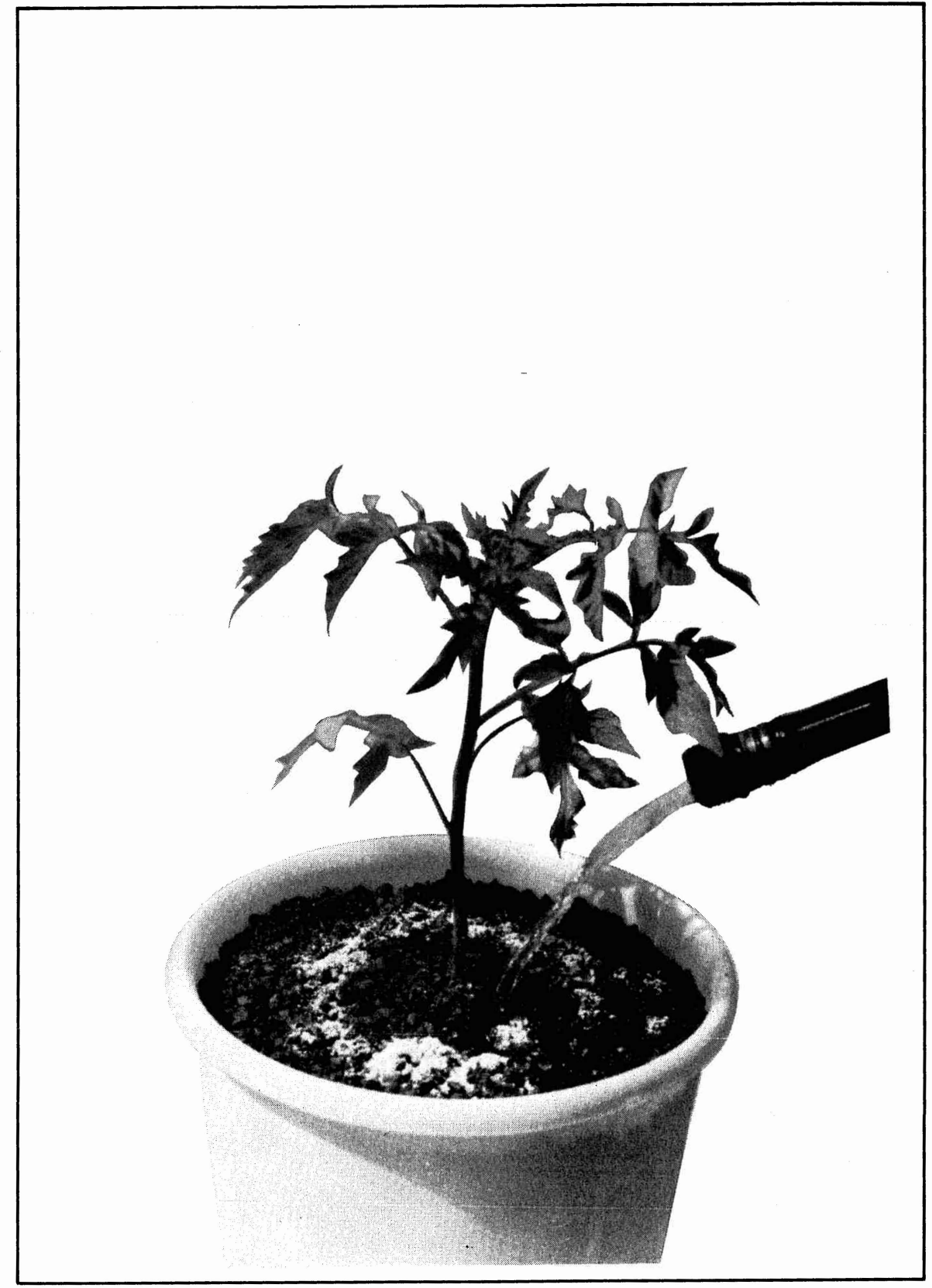

Figure 5. Dry-feeding. Dry fertilizer salts are placed on surface of media and watered in. Media is maintained moist by additions of water as needed. This eliminates the need for nutrient solutions. 


\section{Important Considerations for Growing Plants Without Soil}

The first consideration is the size of the operation. Size depends upon the area available, the reasons for the venture, and the capital to be invested. Adequate financing is essential because expensive installations are required. It may be a year or more before an individual is able to solve technical problems and develop cultural techniques so that his income will pay for maintenance and investment. Above all, market conditions should be thoroughly investigated before making the decision to go into the business. Sufficient labor with the required skills should be assured so that the producer can meet the needs of the operation. Also, supply of required materials of sufficient quality to meet the needs of the operation should be assured.

Once it has been decided to venture into growing plants without soil, the producer must consider these important factors:

- At lower elevations in Hawaii, where there are high levels of sunlight, shade will be required for the plants. Protection from rain is required at certain times of the year to prevent loss of quality and dilution of the solution.

- Wind protection ${ }^{5}$ is required at all locations in Hawaii. A careful study of expected wind conditions in the area should be made. Then, windbreaks to protect the plants against the maximum wind to be

${ }^{5}$ For a discussion of need for windbreaks, see McCall, Wade W., Gordon T. Shiguera, and Yusif N. Tamimi. 1970. Windbreaks in Hawaii. University of Hawaii Coop. Ext. Ser. Circ. 438. expected in the area should be provided. Either constructed or planted windbreaks may be used. Protection from the wind is necessary to reduce mechanical damage to the plants, reduce solution loss to evaporation, and increase the yield and quality of the product.

- The installation should be designed for convenience. Careful planning and engineering will greatly facilitate the use of the installation and reduce the cost of operation.

- Any media placed in the tanks or containers should be free of all toxic, harmful substances. Thorough leaching of tanks and media before use is desirable.

- There is little buffering in the solution in the tanks. This means that relatively rapid changes may occur in the solution, promoting unfavorable conditions for plant growth. Therefore, provisions to maintain adequate levels of nutrients in the solution are necessary.

- A source of good water is necessary for use in making solutions, flushing beds, and cleaning equipment and material.

- Support should be provided for the aerial portion of the plants where needed. This is usually done by use of stakes, by tying on wire supports, or similar methods.

- Adequate storage facilities are required for solutions. The solution should be protected from light to prevent the growth of algae and to help maintain the strength of the solution. 
- Sand and gravel media should be cleaned of old roots and other debris between crops. Media should be flushed to remove accumulated salts. Necessary sanitation measures should be taken to protect against disease and insect infestations. The growing media should be replaced with new material as needed.
- Precautions must be taken to provide good aeration for plant growth. This factor is the most frequent cause of failure in growing plants without soil.

- The grower must exercise careful management in all phases of the operation if it is to be successful.

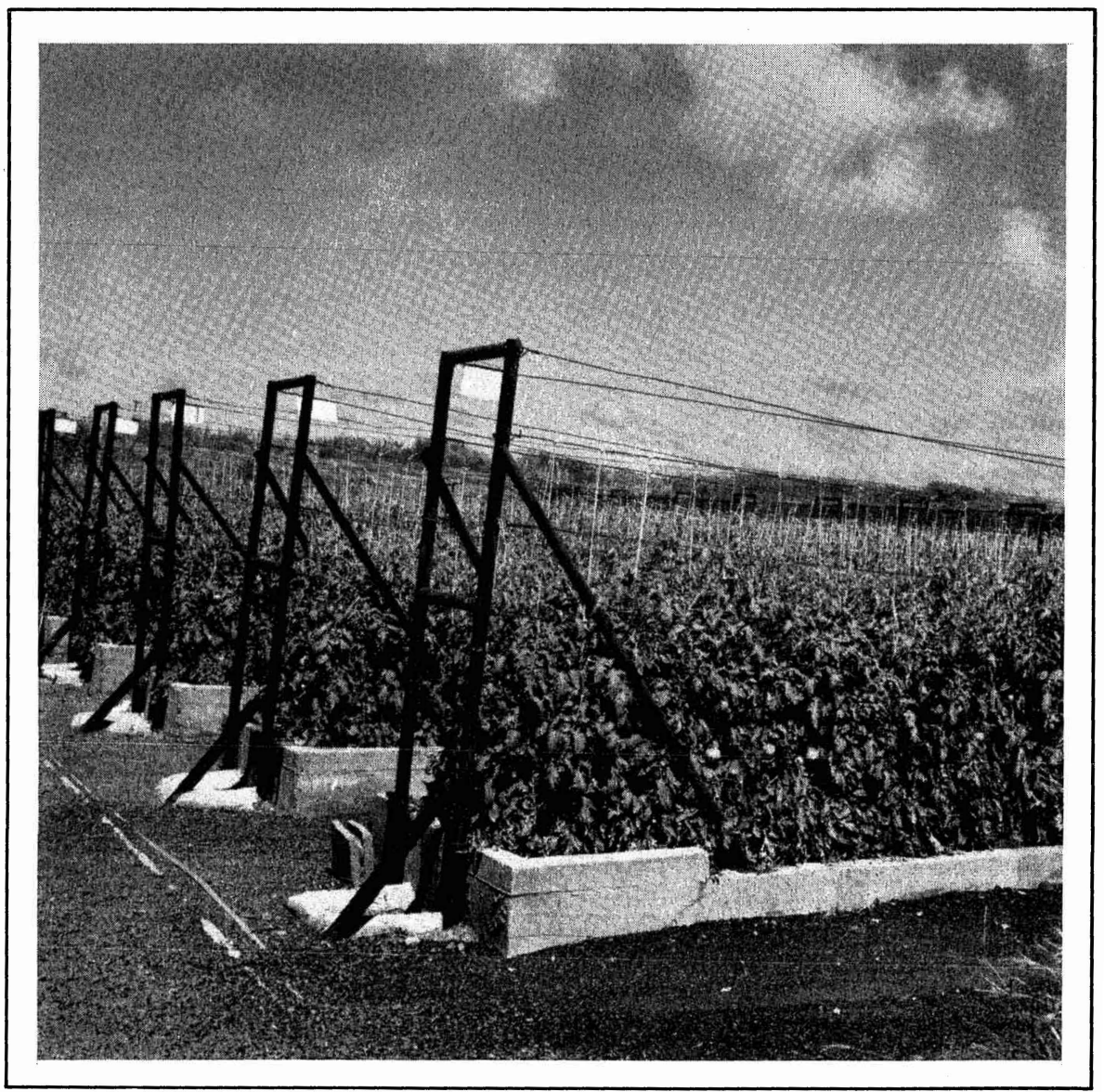

Figure 6. Aerial portions of the plant must be supported where needed. These tomatoes are supported by tying to wire supports above the growing tanks. 




Figure 7. Tanks or containers should be spaced to allow easy access for cultural operations. Actual depth, width and length depend upon the area available, crop to be grown and size of the installation.

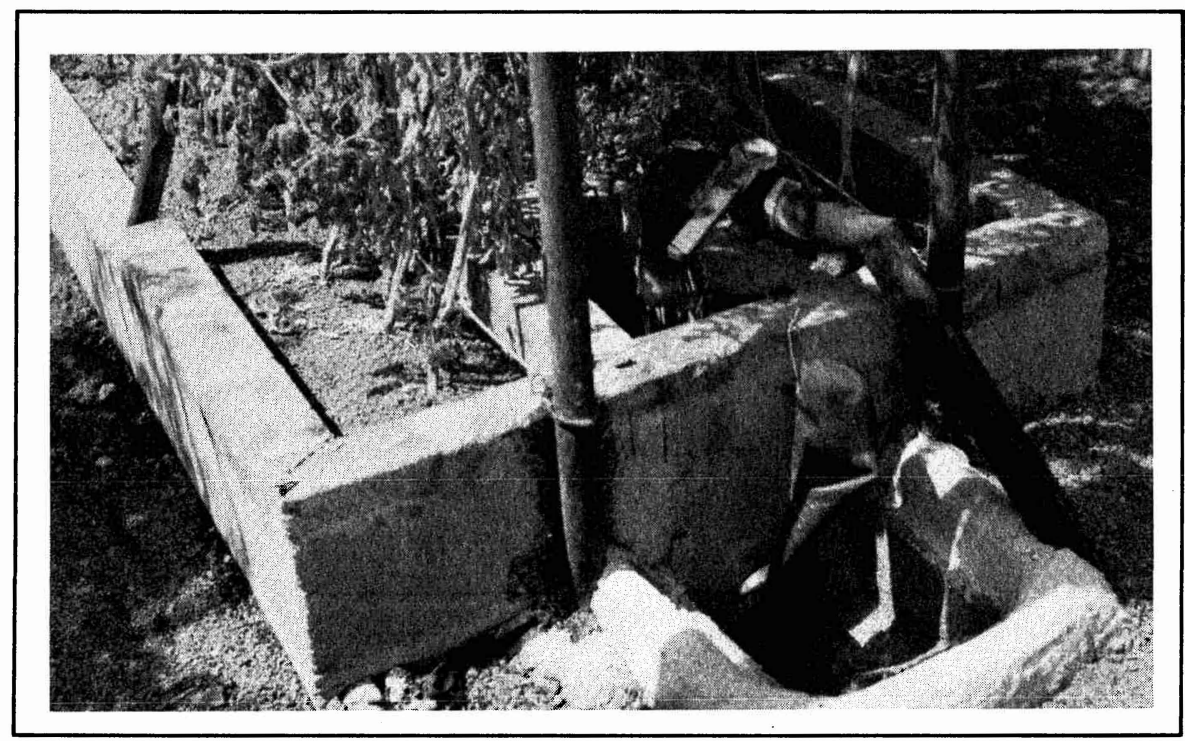

Figure 8. Solutions may be added to the surface of the media in the growing bed or may be added by subirrigation. Solution level should be a minimum of 1 inch from top of the media. Note method of control in this bed. Solutions are added by subirrigation. Level is controlled by closing outlet with tube until desired level is obtained. Drainage occurs when the tube is lowered. 


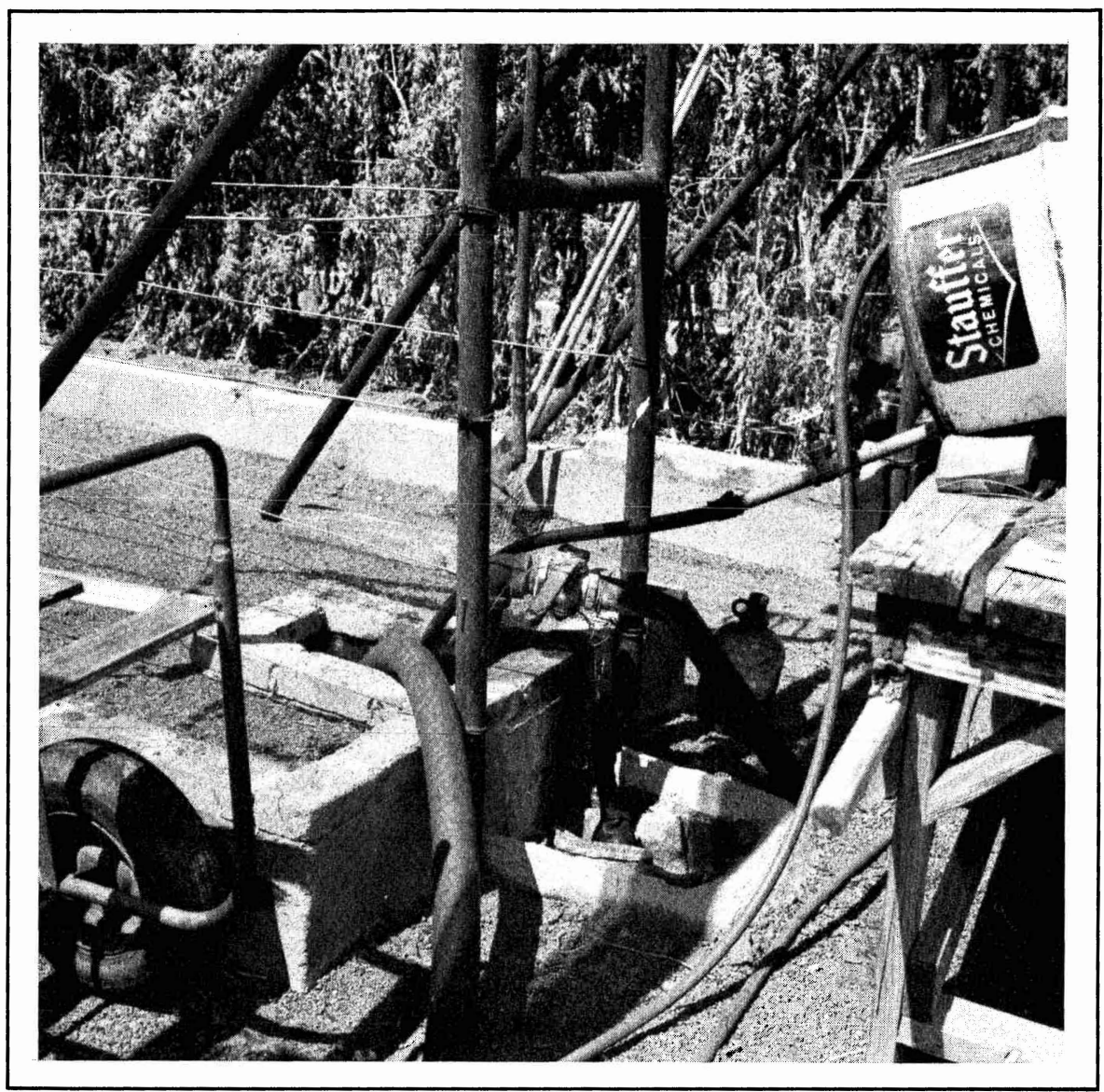

Figure 9. Rigid sanitation measures are required for prevention of disease and insect infestations. Here, a fungicide is being added to a growing bed for disease prevention. Treatments should be done after each crop is harvested. 
A.Constructed windbreaks provide "instant" wind protection. Plastic shade cloth is used in this windbreak.

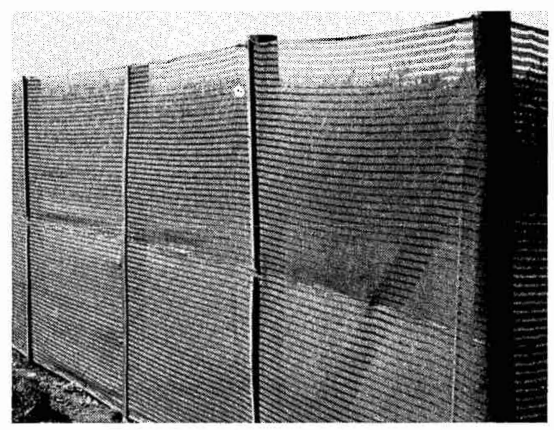

B. Temporary planted materials may be used such as this wild cane.

C. Permanent windbreaks of planted materials are most effective for wind control. Paperbark is used here.
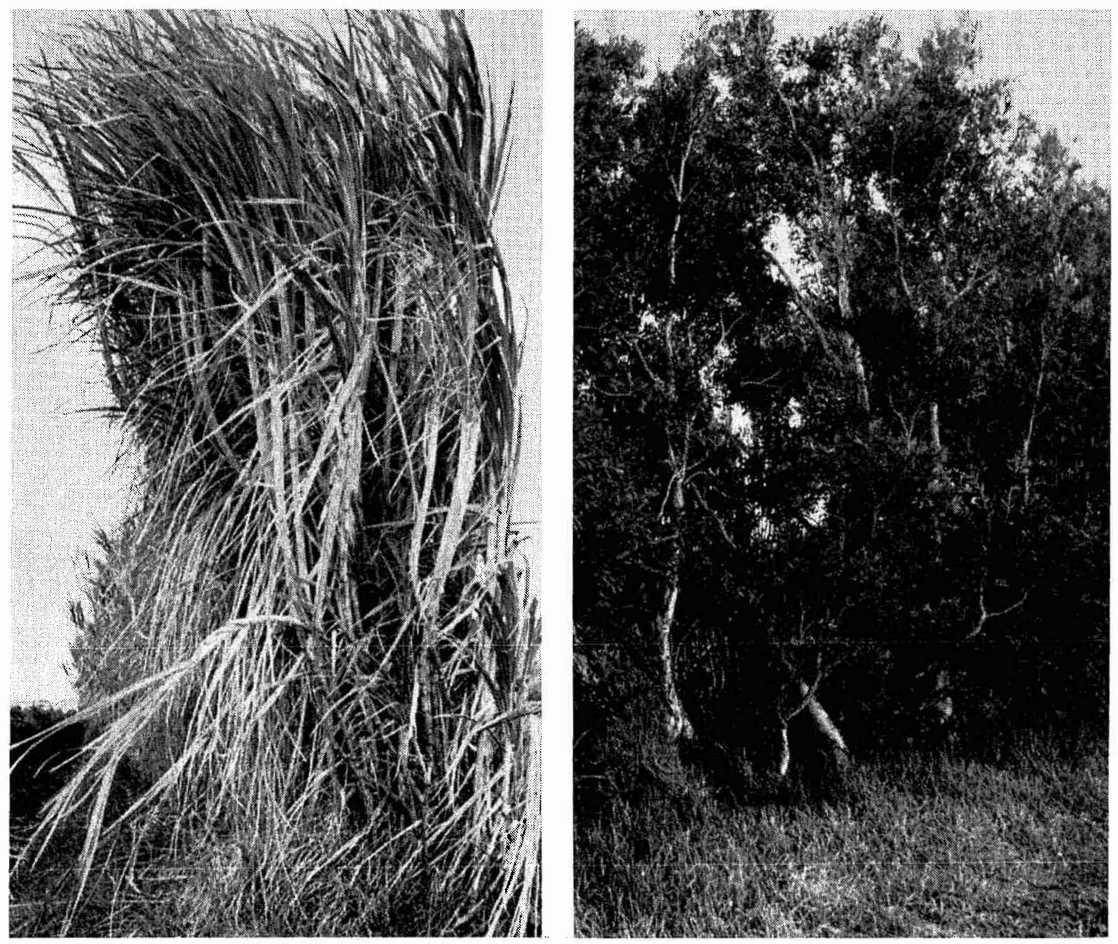

Figure 10. Wind protection is required in Hawaii for crop production. Many types of windbreaks may be used. Windbreaks should not present solid barriers to the wind but allow some wind through to reduce turbulence and promote air circulation. 


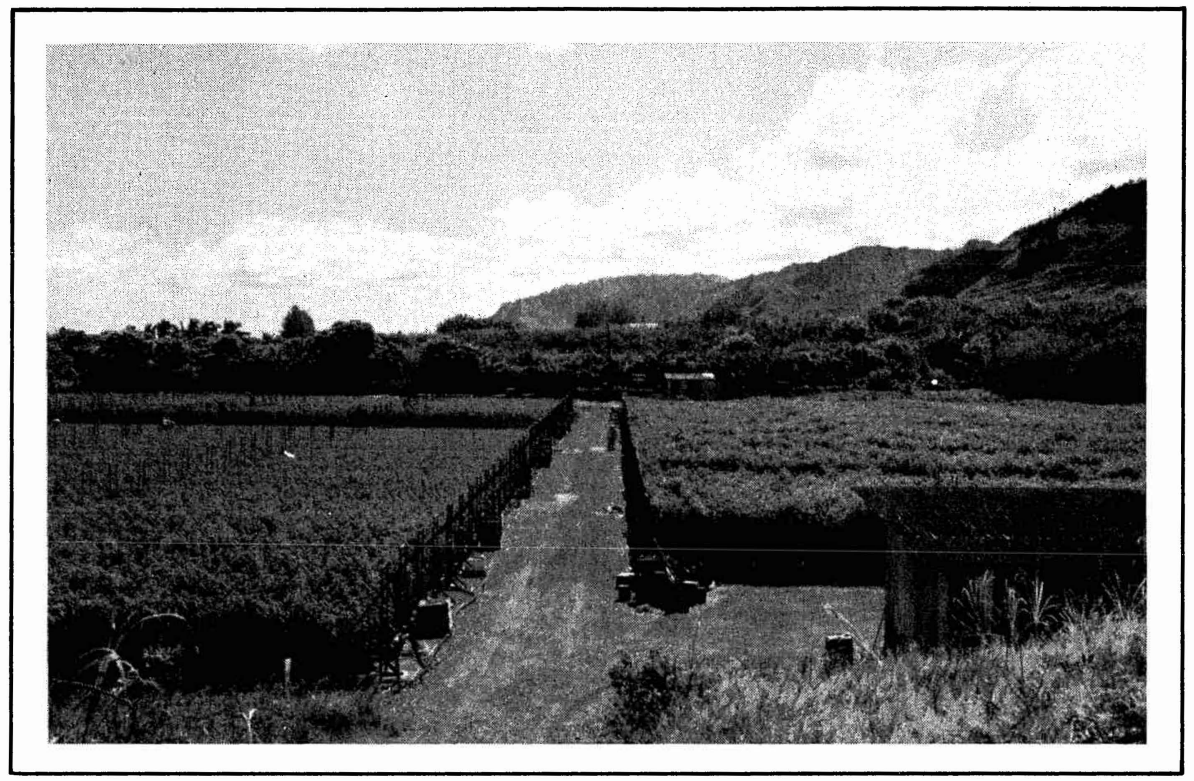

Figure 11. A commercial installation in Hawaii for growing plants in sand culture. Cinders are used in these beds. Careful thought of economic considerations, engineering requirements, and technical factors must be given before locating and building an installation such as this one.



Figure 12. Plants grown by absorbed-nutrient technique. Plant 2 received twice as much exchange resin as Plant 1 . The exchange resin was mixed with silica sand. 


\section{REFERENCES}

(More information on growing plants without soil.)

1. Arnon, D. I., and K. A. Grossenbacher. 1947. Nutrient culture of crops with the use of synthetic ion-exchange materials. Soil Sci. 63: 159-180.

2. Arnon, D. I., and D. R. Hoagland. 1940. Crop production in artificial culture solutions and in soils with special reference to factors influencing yields and absorption of inorganic nutrients. Soil Sci. 50: 463-485.

3. Arnon, D. I., and William R. Meagher. 1947. Factors influencing availability of plant nutrients from synthetic ion-exchange materials. Soil Sci. 64: 213-221.

4. Beeskow, H. C. 1947. Chemical gardening for the amateur. Mich. Agr. Exp. Sta. Quarterly Bull., Vol. 30: 38-50.

5. Beikart, H. M., and C. H. Connors. 1935. The greenhouse culture of carnations in sand. New Jersey Agr. Exp. Sta. Bull. 588.

6. *Bently, Maxwell. 1959. Commercial hydroponics facts and figures. 2nd ed., Bendon Books, Johannesburg.

7. Biebel, J. P. 1958. Hydroponics: the science of growing plants without soil. Florida State Dep. of Agr. Bull. 180.

8. Davidson, O. W. 1946. Large-scale soilless culture for plant research. Soil Sci. 62: 71-86.

9. Edson, S. N. 1968. A successful hydroponic garden for warm climates. Univ. Florida Soils Dep., Gainesville.

10. Ellis, Carleton, M. W. Swaney, and T. Eastwood. 1947. Soilless growth of plants. 2nd ed. Rienhold Publishing Corp., New York.

11. Gericke, W. F. 1929. Aquaculture: a mearis of crop production. Amer. J. Botany. 16: 862.

12. Gericke, W. F., and J. R. Tavernetti. 1936. Heating of liquid culture media for tomato production. Agr. Eng. 17: 141-142, 184.

13. Gericke, W. F. 1938. Crop production without soil. Nature 14: 536-540.

14. Gericke, W. F. 1940. The complete guide to soilless gardening. Prentice-Hall, Inc., New York.

15. Harris, D. A. 1966. Hydroponics: the gardening without soil. Purnell, Cape Town.

16. Hoagland, D. R., and D. I. Arnon. 1938. The water culture method for growing plants without soil. California Agr. Exp. Sta. Cir. 337.

17. 1960 Hydroponics: growing plants in nutrient and nutrient deficient solutions without soil. Turtox Service Leafl. No. 51. General Biological Supply House, Chicago.

18. Kiplinger, D. C., and Alex Laurie. 1942. Growing ornamentals in greenhouse and gravel culture. Ohio Agr. Exp Sta. Bull. 634.

*Probably one of the most comprehensive books available on growing plants without soil. 
19. Kiplinger, D. C., and Alex Laurie. 1948. Growing ornamental greenhouse crops in gravel culture. Ohio Agr. Exp. Sta. Res. Bull. 679.

20. Laurie, Alexander.1948. Soilless culture simplified. McGraw Hill Book Co., New York.

21. Martin, J. P. and C. W. Carpenter. 1939. The growth of plants in water and sand cultures. Hawaiian Planters Record, Vol. XLIII (2): 125-132.

22. Matland, D. R. 1939. Growing plants without soil. Chemical Publishing Co., New York.

23. Miller, E. C. Plant physiology. McGraw-Hill Book Co., New York, N.Y.

24. Nutriculture. War Department Technical Manual TM 20-500.

25. Phillips, A. H. 1940. Gardening without soil. Chemical Publishing Co., Inc., New York.

26. Robbins, W. R. 1946. Growing plants in sand culture for experimental work. Soil Sci. 62: 3-22.

27. Sachs, Julins von. 1887. Lectures on the physiology of plants. Charendon Press, Oxford.

28. Shine, J. W., and W. R. Robbins. Methods of growing plants in solution and sand cultures. New Jersey Agr. Exp. Sta. Bull. 636.

29. Stout, J. G., and M. E. Marvel. 1959. Hydroponic culture of vegetable crops. Florida Agr. Ext. Serv. Cir. 192.

30. Turner, W. I., and Victor M. Henry. 1939. Growing plants in nutrient solution or scientifically controlled growth. John Wiley and Sons, Inc., New York.

31. Withrow, R. B., and J. B. Biebel. 1936. A sub-irrigation method of supplying nutrients to plants growing under commercial and experimental conditions. J. Agr. Res. 33: 693-702.

32. Withrow, R. B., and Alice P. Withrow. 1948. Nutriculture. Indiana (Purdue Univ.) Agr. Exp. Sta. S. C. 328. 
Hawaii residents may order single copies of publications free of charge from county offices. Out-of-State inquiries or bulk orders should be sent to the Agricultural Publications and Information Office, College of Tropical Agriculture and Human Resources, 2500 Dole Street, Krauss Hall Room 107, Honolulu, Hawaii 96822. Price per copy to bulk users, $\$ .50$ plus postage.

Issued in furtherance of Cooperative Extension Work, Acts of May 8 and June 30, 1914, in cooperation with the U.S. Department of Agriculture, and Director and Interim Dean Noel P. Kefford, College of Tropical Agriculture and Human Resources, University of Hawaii at Manoa, Honolulu, Hawaii 96822. An Equal Opportunity Employer providing programs and services to the Citizens of Hawaii without regard to race, color, national origin or sex. 